\title{
The Mixing State of Polar Stratospheric Cloud Particles in "Sandwich Structure" Observed by Lidar 1. Determination of the Mixing State of PSC Particles
}

\author{
Diana DANEVA \\ Graduate School of Science, Nagoya University, Nagoya, Japan \\ Takashi SHIBATA, Yasunobu IWASAKA \\ Graduate School of Environmental Studies, Nagoya University, Nagoya, Japan \\ Masahiro NAGATANI \\ Solar Terrestrial Environment Laboratory, Nagoya University, Nagoya, Japan \\ Kouichi SHIRAISHI, Masahiko HAYASHI, Motowo FUJIWARA \\ Faculty of Science, Fukuoka University, Fukuoka, Japan \\ and \\ Roland NEUBER \\ Alfred Wegener Institute for Polar and Marine Research, Research Unit Potsdam, Germany
}

(Manuscript received 22 September 2002, in revised form 7 April 2003)

\begin{abstract}
The mixing state of polar stratospheric cloud (PSC) particles in the vertical sandwich structure observed simultaneously by lidar, and by Optical Particle Counter (OPC) above Ny Ålesund on $6^{\text {th }}$ January 1996, is investigated. The vertical sandwich structure of PSC (observed by lidar) is characterized by one layer that exhibits large backscattering and low depolarization enclosed between two layers that exhibit low backscattering and high depolarization. The assumption that the observed optical properties of the cloud can be explained by an external mixture of solid and liquid particles is used as a basis for developing a new scheme for interpreting the lidar data. The backscatter and depolarization ratios observed by lidar are employed in equations, that allow for the separate calculation of the backscattering coefficients of the liquid and the solid particles, and for clear distinction of the mixing state of the cloud. Utilization of the developed scheme to analyze the vertical profile of the investigated PSC observed by lidar reveals that no purely liquid or solid layers exist, and that the entire altitude of the cloud can be represented by an external mixture of solid and liquid particles. Comparison of the vertical profiles of the
\end{abstract}

Corresponding author: Takashi Shibata, Graduate School of Environmental Studies, Nagoya University, Chikusa-ku, Nagoya 464-8601, Japan.

E-mail: tshibata@stelab.nagoya-u.ac.jp

(C) 2003, Meteorological Society of Japan 
calculated backscattering coefficients of the solid and liquid particles observed by lidar, and the number concentrations of the particles in different size categories observed by the Optical Particle Counter (OPC) implies radiuses of greater than $1.8 \mu \mathrm{m}$, and number concentrations of around $10^{-4}-10^{-3} \mathrm{~cm}^{-3}$ for the solid particles.

\section{Introduction}

Although the existence of Polar Stratospheric Clouds (PSCs) has been acknowledged for over a century (Stanford and Davis 1974), extensive research of these clouds began only after recognition of the important role they play in the ozone destruction processes in the polar regions (e.g., Solomon et al. 1986). Their properties have been investigated by means of remote and in situ observations, laboratory experiments and theoretical simulations. Two types of PSC have been identified according to their formation temperature: Type I, forming at temperatures above the frost point $\left(T_{I C E}\right)$ and Type II, forming below the frost point. The distinction between these two main types derives from analysis of lidar observations (Poole and McCormick 1988).

While type II PSCs are believed to be composed of ice crystals (Steel et al. 1983), the phase and the composition of type I PSCs are still under debate. Type I PSCs have been subdivided into types Ia and Ib (Browell et al. 1990). It is thought that Type Ib particles are mainly composed of liquid supercooled ternary solution (STS), droplets of $\mathrm{HNO}_{3}, \mathrm{H}_{2} \mathrm{SO}_{4}$, and $\mathrm{H}_{2} \mathrm{O}$ (Carslaw et al. 1994; Drdla et al. 1994). Type Ia PSCs are assumed to be composed of solid nitric acid containing particles, although their exact composition has not been determined. The main source of uncertainty in their chemical composition is that their formation mechanism is not understood (Tolbert 1994). Candidates for type Ia particles are NAT (nitric acid tri-hydrate) (e.g., Crutzen and Arnold 1986; Hanson and Mauersberger 1988), NAD (nitric acid di-hydrate) (Worsnop et al. 1993), NAT nucleated on SAT (sulfuric acid tetrahydrate) (Iraci et al. 1998), amorphous solid solutions of nitric and sulfuric acids (e.g., Tabazadeh et al. 1994), etc.

However, as has been shown by Rosen et al. (1997), Gobbi et al. (1998), Shibata et al. (1999), and Biele et al. (2001), some of the PSC observations can be interpreted as a mixture of coexisting solid and liquid particles. On the basis of the color index derived by backscatter sonde measurements, Rosen et al. (1997) suggested the existence of a PSCs type M (for mixture), whose optical properties are consistent with a mixture of Type Ia and Type Ib particles. Shibata et al. (1999) have suggested an external mixture of liquid and solid particles for the composition of the lidar observed PSCs on the basis of an investigation of the simultaneous evolution of the backscatter and depolarization ratios along the back-trajectory of the cloud. Gobbi et al. (1998) have shown that mixed-phase clouds commonly occur in the Antarctic throughout the winter. The detection of the mixed phase in the PSCs is based on the assumption of the existence of a typical linear depolarization ratio of the solid particles. Biele et al. (2001) have used the perpendicularly polarized backscatter ratio as an indicator for the presence of solid particles in a PSC. The analysis of their data set from lidar observations of PSCs above $\mathrm{Ny}$ Allesund reveals the nonequilibrium coexistence of solid and liquid particles to be a common state in the Arctic.

Here, a PSC event observed by lidar and OPC above Ny Ålesund on the $6^{\text {th }}$ January 1996 is investigated in the context of the abovecited works. The assumption of the cloud being an external mixture of solid and liquid particles is used as a base for developing a new scheme for interpreting the lidar data. The backscatter and depolarization ratios observed by lidar are employed in equations that allow separate calculation of the backscattering coefficients of the liquid and solid particles, and clear distinction of the mixing state of the cloud. In the companion paper (Part 2), the observed optical properties of the solid and liquid particles are simulated in a microphysical/optical model by means of an external mixture of NAT and STS particles.

\section{Lidar system and observed parameters}

The lidar data used in the present analysis were collected with the Nd:YAG lidar installed 
in $\mathrm{Ny}$ Ålesund, Spitsbergen $\left(79^{\circ} \mathrm{N}, 12^{\circ} \mathrm{E}\right)$ by Nagoya University and Fukuoka University. The system is operated at the fundamental $(1.064 \mu \mathrm{m})$ and second harmonic $(0.532 \mu \mathrm{m})$ wavelengths of the Nd:YAG laser. The $532 \mu \mathrm{m}$ laser beam is linearly polarized, and is used to observe the polarization properties of PSCs. As an output of the lidar system, signals in three channels are available, one perpendicular to and one parallel to the polarization plane of the emitted laser beam at $532 \mathrm{~nm}$, and a nonpolarized one at $1064 \mathrm{~nm}$. A more detailed description of the lidar system can be found in Shibata et al. (1997) and in Adachi et al. (2001).

The parameters derived from the lidar data with the three channels are the backscatter ratio $R$ at $0.532 \mu \mathrm{m}$, the depolarization ratio $\delta$ at $0.532 \mu \mathrm{m}$ and the Angstrom exponent $\alpha$. The backscatter ratio is defined as the ratio of the total backscattered signal from the atmosphere to the backscattered signal from the atmospheric molecules alone:

$$
R=\frac{\beta_{\text {Ray }}+\beta_{\text {Mie }}}{\beta_{\text {Ray }}},
$$

where $\beta_{\text {Ray }}=\beta_{\text {Ray }}^{\perp}+\beta_{\text {Ray }}^{\mathrm{II}}$ and $\beta_{\text {Mie }}=\beta_{\text {Mie }}^{\perp}+\beta_{\text {Mie }}^{\mathrm{II}}$ are the total Rayleigh and Mie (aerosol) backscattering coefficients. The backscattering coefficients for the perpendicular and the parallel components of the backscattered signal are denoted by $\perp$ and II. The depolarization ratio $\delta$ is defined as the ratio of the perpendicularly polarized component of the backscattered signal to the total backscattered signal:

$$
\delta=\frac{\beta_{R a y}^{\perp}+\beta_{M i e}^{\perp}}{\beta_{R a y}+\beta_{M i e}} .
$$

In the calculation of $\delta$, the possible influence of the incomplete polarization of the emitted laser light, and of the cross talk signal of the detector between the parallel and the perpendicular channels have been taken into account (Adachi et al. 2001).

The Angstrom exponent, $\alpha$, is calculated using the dependence of the aerosol backscattering coefficient on the wavelength (i.e. $\beta_{\text {Mie }} \propto \lambda^{-\alpha}$ ) and is defined as:

$$
\alpha=-\frac{\ln \left(\beta_{\text {Mie }}\left(\lambda_{2}\right) / \beta_{\text {Mie }}\left(\lambda_{1}\right)\right)}{\ln \left(\lambda_{2} / \lambda_{1}\right)},
$$

where $\lambda_{1}$ and $\lambda_{2}$ are respectively the second harmonic and the fundamental wavelengths of the laser. $\beta_{\text {Mie }}\left(\lambda_{1}\right)$ and $\beta_{\text {Mie }}\left(\lambda_{2}\right)$ are the total backscattering coefficients at these wavelengths. They are estimated as $\beta_{\text {Mie }}=(R-1) \beta_{\text {Ray }}$ for each wavelength. The corresponding backscatter ratios are calculated by an iterative method (Shibata et al. 1996). The molecular backscattering coefficient, $\beta_{R a y}$, is calculated using the pressure and temperature profiles obtained by the aerological sondings performed daily at Ny Ålesund. The bandwidth of the interference filters is $1 \mathrm{~nm}$ full width half maximum (FWHM), which implies a value of $0.5 \%$ for the molecular depolarization at $532 \mathrm{~nm}$, defined as $\delta_{\text {Ray }}=\beta_{\text {Ray }}^{\perp} / \beta_{\text {Ray }}$ (Adachi et al. 2001).

The value of $R-1$ is roughly proportional to the mass mixing ratio of the particulate matter (e.g., Pinnick et al. 1980) and hence describes the altitude-distribution of the total mass condensed on aerosols. The Ångstrom exponent, $\alpha$, is a measure of the sizes of the particles in the scattering volume. Large values of $\alpha$ can be associated, in general, with abundance of particles having radiuses smaller than the lidar wavelengths and vice versa. The depolarization ratio $\delta$ is a measure of the asphericity of the aerosol particles and shows what part of the total backscattered signal has a plane of polarization that is perpendicular to the plane of the initially linearly polarized laser beam. If the observed particles were perfect spheres, they would not give rise to any perpendicular polarization of the returned signal, and correspondingly for them $\beta_{\text {Mie }}^{\perp}=0$. For any other shape of the particles, some polarized component is expected.

The definition of $\delta$ includes the depolarization from atmospheric molecules. This means that for pure molecular atmosphere $(R=1)$ the depolarization ratio equals the molecular depolarization $\left(\delta=\delta_{\text {Ray }}\right)$. If the observed volume gives $\delta>\delta_{\text {Ray }}$, then the presence of some depolarizing particles is indicated, while $\delta<\delta_{\text {Ray }}$ roughly indicates the presence of nondepolarizing particles. If, however, the observed volume consists of an external mixture of solid and liquid particles, the interpretation of the value of $\delta$ is not straightforward. It can be less or higher than $\delta_{\text {Ray }}$, depending on the amount and the optical properties of the constituent solid and liquid particles. One could observe $\delta<\delta_{\text {Ray }}$, and at the same time have some amount of solids masked by large mass of liquid droplets. 
In other words, the depolarization ratio alone does not allow for detection of mixed phase clouds. (For details, see Adachi et al. (2001).)

\section{Determination of the mixing state of PSCs}

\subsection{Methodology}

For an external mixture of liquid (perfect spheres) and solid (non-spherical) particles, the depolarization ratio (2) can be expressed as:

$$
\begin{aligned}
\delta & =\frac{\beta_{l i q}^{\perp}+\beta_{\text {sol }}^{\perp}+\beta_{\text {Ray }}^{\perp}}{\beta_{\text {liq }}+\beta_{\text {sol }}+\beta_{\text {Ray }}} \\
& =\frac{0 \times \beta_{l i q}+\delta_{\text {sol }} \times \beta_{\text {sol }}+\delta_{\text {Ray }} \times \beta_{\text {Ray }}}{\beta_{\text {liq }}+\beta_{\text {sol }}+\beta_{\text {Ray }}},
\end{aligned}
$$

where $\delta_{R a y}=\beta_{\text {Ray }}^{\perp} / \beta_{\text {Ray }}$ is the depolarization of atmospheric molecules and $\delta_{\text {sol }}=\beta_{\text {sol }}^{\perp} / \beta_{\text {sol }}$ is the depolarization ratio of the solid particles. The backscatter ratio $R$ can be also expressed as:

$$
R=\frac{\beta_{l i q}+\beta_{\text {sol }}+\beta_{\text {Ray }}}{\beta_{\text {Ray }}} .
$$

Examination of equations (4) and (5) shows that these are two linear equations for the unknown values $\beta_{l i q}$ and $\beta_{\text {sol }}$, containing only one other unknown parameter, namely $\delta_{\text {sol }}$. Hence, the total backscattering coefficients of the liquid and solid particles could be expressed as:

$$
\begin{aligned}
& \beta_{\text {liq }}=\left(\delta_{\text {sol }}(R-1)-\left(\delta R-\delta_{\text {Ray }}\right)\right) \frac{\beta_{\text {Ray }}}{\delta_{\text {sol }}}, \\
& \beta_{\text {sol }}=\left(\delta R-\delta_{\text {Ray }}\right) \frac{\beta_{\text {Ray }}}{\delta_{\text {sol }}},
\end{aligned}
$$

and knowing $\delta_{\text {sol }}$ would allow the calculation of $\beta_{\text {liq }}$ and $\beta_{\text {sol }}$ separately.

For the limiting cases when the scattering volume consists entirely of liquid or solid particles, i.e., when $\beta_{\text {sol }}=0$ or $\beta_{l i q}=0$, equations (6) and (7) lead to the values of the depolarization ratio:

$$
\begin{aligned}
& \delta_{\text {liq.only }}=\frac{\delta_{R a y}}{R}, \\
& \delta_{\text {sol.only }}=\frac{\delta_{\text {sol }}(R-1)+\delta_{\text {Ray }}}{R} .
\end{aligned}
$$

Hence, $\delta_{\text {liq.only }}$ will be observed if all of the aerosol particles in the scattering volume are liquid, and $\delta_{\text {sol.only }}$ will be observed if all the particles are solid with depolarization ratio $\delta_{\text {sol }}$. If an external mixture of solid and liquid par- ticles is observed, the observed $\delta$ will take values between $\delta_{\text {liq.only }}$ and $\delta_{\text {sol.only. }}$. As a result, the mixing state of the cloud can be distinguished by comparing $\delta$ with these values.

The value of $\delta_{\text {liq.only }}$ (equation (8)) does not depend on the value $\delta_{\text {sol }}$, so it can be used as a criterion to distinguish between the liquid only and any other type of mixing state of a PSC, even if the value of $\delta_{s o l}$ is unknown. However, the calculation of $\delta_{\text {sol.only }}, \beta_{\text {liq }}$ and $\beta_{\text {sol }}$ from Equations (6), (7) and (9) requires knowledge of the depolarization ratio of the solid particles $\delta_{\text {sol }}$.

Some reports on the observed depolarization ratios of the solid particles in PSCs make use of the definition $\delta_{\text {sol }}^{\prime}=\beta_{\text {sol }}^{\perp} / \beta_{\text {sol }}^{\mathrm{II}}$, which is equivalent to $\delta_{\text {sol }}=\delta_{\text {sol }}^{\prime} /\left(\delta_{\text {sol }}^{\prime}+1\right)$ in the notation used here. Kent et al. (1990) have reported the airborne lidar-observed depolarization of solid particles in Arctic PSCs to be a relevant constant at $\delta_{\text {sol }}^{\prime} \approx 60 \%$ (or $\delta_{\text {sol }} \approx 37 \%$ ). Gobbi et al. (1998) have shown that the depolarization of solid PSCs in the Antarctic could also be considered to have a constant value on the order of $\delta_{\text {sol }}^{\prime} \approx 50 \%$ (or $\delta_{\text {sol }} \approx 33 \%$ ). Adachi (1996), and Adachi et al. (2001) have found that for PSCs observed above Ny Ålesund, a stable state of the nonspherical particles exist with value of $\delta_{\text {sol }} \approx 35 \%$. Shibata (1999) has shown the value of $30 \%$ for the depolarization ratio of the solid particles to be a good assumption for the interpretation of the lidar observed sandwich structure PSCs, since the solid particles grow rapidly to sizes where scattering computations imply $\delta_{\text {sol }} \gtrsim 30 \%$.

Here the value of $\delta_{s o l}=30 \% \pm 10 \%$ will be used for the depolarization ratio of the solid particles, which covers the interval of $\delta_{\text {sol }}^{\prime}$ between 25 and $67 \%$. The absolute error of $\delta_{\text {sol }}$ is taken to be $10 \%$, so as to include a realistic range of $\delta_{s o l}$ in the analysis.

From equation (6) solved for the case $\beta_{l i q} \geq 0$, a limiting expression for the value of $\delta_{\text {sol }}$ can be derived:

$$
\delta_{s o l} \geq \frac{\delta R-\delta_{R a y}}{R-1}=\delta_{\text {sol }}^{\min }, \quad R \neq 1 .
$$

$\delta_{\text {sol }}^{\min }$ is the value of the depolarization ratio of the solid particles that would allow for the explanation of the observed $R$, and $\delta$ in terms of scattering volume consisting of solid particles only. It can be also thought of as the minimal 


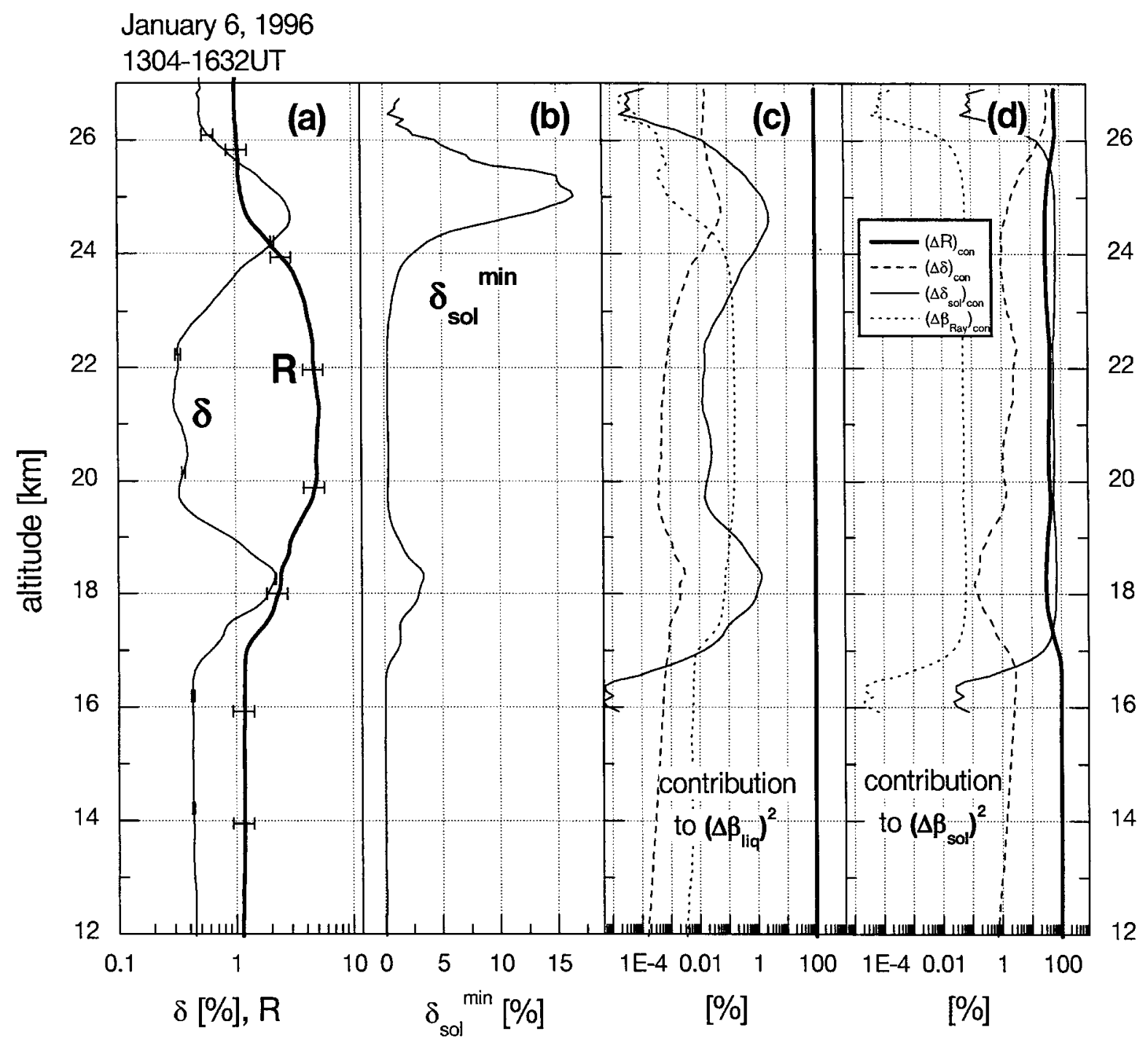

Fig. 1. Estimates for the value of $\delta_{\text {sol }}^{\min }$ (eq. 10) and the percentage contribution of the uncertainties in $R, \delta, \delta_{\text {sol }}$ and $\beta_{\text {Ray }}$ (i.e., of the four terms in Eq. 11) to the variance of $\beta_{\text {liq }}$ and $\beta_{\text {sol }}$ for the vertical profile of PSC, observed by lidar on January 6, 1996.

(a) The observed backscatter ratio $(R)$ (thick line) and depolarization ratio $(\delta)$ (thin line). The error bars represent $2 \sigma$; (b) Estimates for the value of $\delta_{\text {sol }}^{\mathrm{min}}$ (Eq. 10); Percentage contribution of the uncertainties in $R$ (thick solid line), $\delta$ (dashed line), $\delta_{\text {sol }}$ (thin solid line) and $\beta_{\text {Ray }}$ (dotted line) to the variances $\left(\Delta \beta_{l i q}\right)^{2}(\mathrm{c})$ and $\left(\Delta \beta_{\text {sol }}\right)^{2}(\mathrm{~d})$.

possible value of $\delta_{\text {sol }}$, to produce the observed set of $R$ and $\delta$.

Figures 1 (a) and (b) show the vertical profiles of the observed $R$ and $\delta$ and the calculated $\delta_{\text {sol }}^{\min }$ for the PSC observed on January $6^{\text {th }}, 1996$, which is the case investigated in this paper. The largest value of $\delta_{\text {sol }}^{\min }$ is $17 \%$ at the altitude of $25 \mathrm{~km}$, where the maximum in $\delta$ is accom- panied by a small value of $R$. The solid particles at this altitude cannot have a $\delta_{\text {sol }}$ smaller than $17 \%$ according to Eq. (10), and the value is close to the lower limit of $\delta_{\text {sol }}$ (20\%: $30 \%$ minus 10\%), chosen for the range of the possible values of $\delta_{s o l}$. If the layer is composed of only solid particles at this altitude, the particles should have a $\delta_{\text {sol }}$ value of $17 \%$. 


\subsection{Uncertainties and error analysis}

The absolute error $(1 \sigma)$ of $R, \delta$ and $\alpha$ was calculated for each data point in the altitude range of the lidar data. The relative error, $\Delta R / R$, has an approximately steady value of about $20 \%$ and the relative error, $\Delta \delta / \delta$, is on the order of 1 to $10 \%$. The relative error of the Rayleigh backscattering coefficient is assumed to have a value of $1 \%$ as a result of the uncertainties in the molecular density measurements (Russell et al. 1979). The uncertainty of $\alpha$ is around $20 \%$.

The absolute errors of $\beta_{l i q}$ and $\beta_{\text {sol }}\left(\Delta \beta_{l i q}\right.$ and $\Delta \beta_{\text {sol }}$ ) were calculated from Equations (6) and (7), with the absolute error of $\delta_{\text {sol }}\left(\Delta \delta_{\text {sol }}\right)$ taken to be $10 \%$. The analysis of the propagation of the error ignoring the cross-correlation terms is performed according to:

$$
\begin{aligned}
\left(\Delta \beta_{l i q}\right)^{2}= & (\Delta R)^{2}\left(\frac{\partial \beta_{l i q}}{\partial R}\right)^{2}+(\Delta \delta)^{2}\left(\frac{\partial \beta_{l i q}}{\partial \delta}\right)^{2} \\
& +\left(\Delta \delta_{\text {sol }}\right)^{2}\left(\frac{\partial \beta_{l i q}}{\partial \delta_{\text {sol }}}\right)^{2} \\
& +\left(\Delta \beta_{\text {Ray }}\right)^{2}\left(\frac{\partial \beta_{l i q}}{\partial \beta_{\text {Ray }}}\right)^{2} .
\end{aligned}
$$

The same Equation holds for $\beta_{\text {sol }}$. The vertical profiles of the percent contributions of the uncertainties in $R, \delta, \delta_{\text {sol }}$ and $\beta_{\text {Ray }}$ (i.e. the four terms in Eq. 11) to the variance of $\beta_{\text {liq }}$, and $\beta_{\text {sol }}$, are shown in Figures 1 (c) and (d). It can be seen that the main source of error in both cases is the uncertainty in the backscattering ratio $R$ (thick solid line). In the case of $\beta_{l i q}$ the contribution of the uncertainty in $\delta_{\text {sol }}$ (thin solid line) is less than $10 \%$, in contrast to the contribution of the uncertainty in $R$ of more than $90 \%$. In the case of $\beta_{\text {sol }}$, the contributions of the uncertainty in $R$ and $\delta_{\text {sol }}$, are of the same order (between 30 and $60 \%$ ) at the altitude range of interest (between 17 and $26 \mathrm{~km}$ ). The contributions of the uncertainties in $\delta$ (dashed line) and $\beta_{\text {Ray }}$ (dotted line) are less than $10 \%$ in both cases.

\section{Data analysis and interpretation}

The lidar system described in section 2 has been in operation since 1993 and a 10-year record of PSC observations is available. During this period, several concomitant in situ measurements of the vertical distribution of the aerosol size, and number concentrations, were performed by balloon-born OPC at Ny Ålesund. The instrument and the collected data are described by Hayashi et al. (1998). Here, the case of a PSC observed simultaneously by lidar and OPC on January $6^{\text {th }}, 1996$ is investigated.

The observation site at Ny Ålesund lies near the center of the Arctic vortex during most of the consecutive winters from 1989/1990 to 1996/1997. The PSCs above Ny Ålesund are not affected by local orographic effects, and hence can be considered as a product of the slowly varying synoptic conditions of the Arctic vortex center (Biele et al. 2001).

The vertical profiles of $R, \delta$ and $\alpha$, observed by lidar on January $6^{\text {th }}, 1996$ are shown in Fig. 2. The detected PSCs exhibit the so-called "sandwich structure" (Shibata et al. 1997). The sandwich structure is characterized by one layer with large $R\left(R_{\max } \approx 4-8\right)$ and low depolarization $(\delta<0.5 \%)$ enclosed between two layers with low $R(R<2)$ and high depolarization $\left(\delta_{\max } \approx 1-2 \%\right)$. The value of $\alpha$ can vary between 0.5 and 1.3 at the altitude of $R_{\max }$ (Shi-

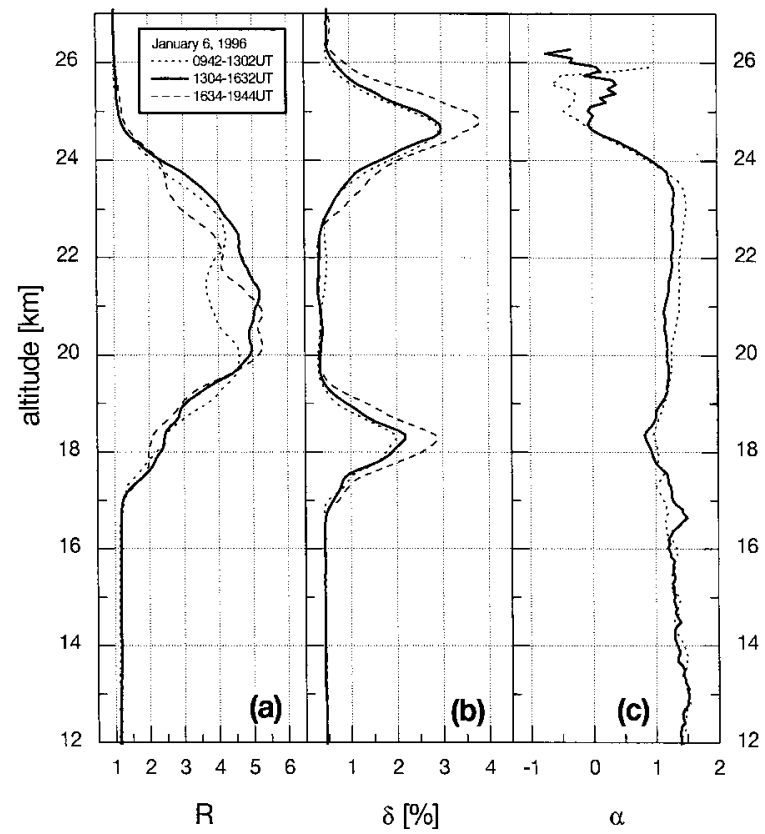

Fig. 2. Lidar observed profiles of the backscatter ratio $R$ (a), depolarization ratio $\delta$ (b) and Ångstrom exponent $\alpha$ (c) for January 6, 1996. 
bata et al. 1999). For the case shown in Fig. 2, the PSCs maintained similar vertical sandwich structure for 10 hours. The horizontal extent of the structure is estimated to be several hundred kilometers according to the wind velocity in the lower stratosphere. The profiles shown in Fig. 2 are derived by averaging the raw lidar data (10 minutes original resolution) for 3 to 4 hours intervals in order to increase the statistical stability of the signal. The use of such large averaging intervals is acceptable since the raw data shows well-defined layer structure and slow variability of the optical properties of the PSC along the time of the observations.

\subsection{Determination of the mixing state from lidar data}

Figure 3 (a) shows the vertical profiles of $R, \delta$ and $\alpha$ for the time interval concomitant with the OPC observations (Fig. 3 (d)), followed by

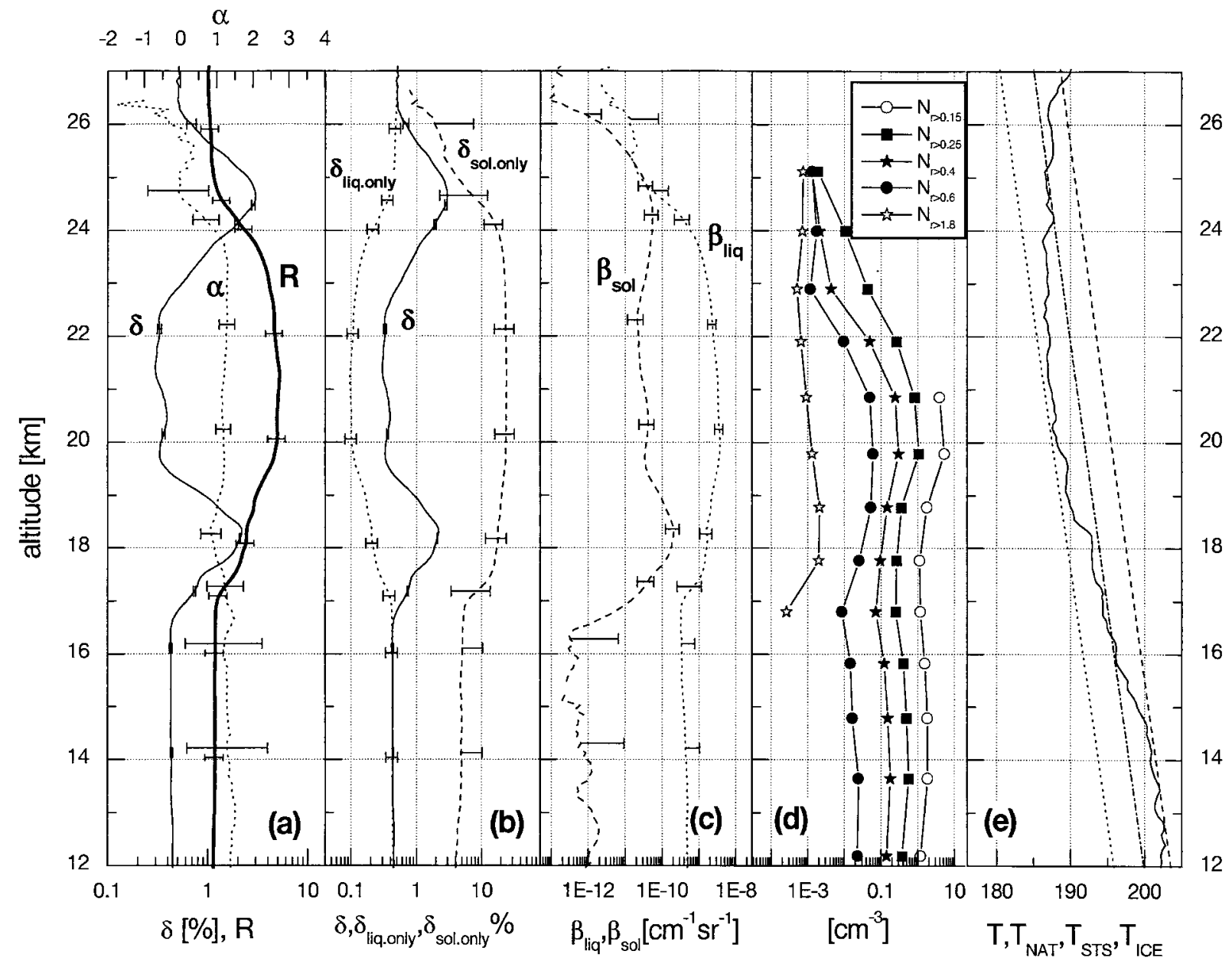

Fig. 3. PSC observed simultaneously by lidar and OPC on January 6, 1996:

(a) $R, \delta$ and $\alpha$ (1304-1632UT); (b) Depolarization ratios $\delta_{\text {liq.only }}$ (dotted line) and $\delta_{\text {sol.only }}$ (dashed line), calculated according to equations (8) and (9) (see text) and the observed $\delta$ (solid line); (c) $\beta_{\text {liq }}$ and $\beta_{\text {sol }}$ calculated from equations (6) and (7); (d) The number concentration of the particles with radiuses $>0.15$ (hollow circles), 0.25 (solid squares), 0.4 (solid stars), 0.6 (solid circles) and $1.8 \mu \mathrm{m}$ (hollow stars) in particles $\mathrm{cm}^{-3}$; and, (e) Temperature profile observed by sonde launched with the OPC (solid line), $T_{N A T}$ (dashed line), $T_{I C E}$ (dotted line) and $T_{S T S}$ (dash-dotted line) estimated for 5 ppmv $\mathrm{H}_{2} \mathrm{O}$ and 15 ppbv $\mathrm{HNO}_{3}$.

The error bars represent $2 \sigma$. When the value of the standard deviation is larger than the variable itself, the error bars in the minus direction are not shown. 
the vertical profiles of $\delta_{\text {liq.only }}, \delta$ and $\delta_{\text {sol.only }}$ (Fig. 3 (b)) and $\beta_{\text {liq }}$ and $\beta_{\text {sol }}$ (Fig. 3 (c)), calculated as explained in section 3.1. The error bars depict two standard deviations at representative altitudes. Examination of Fig. 3 (b) reveals that at the altitude range of the sandwich structure (from 17 to $26 \mathrm{~km}$ ) there is no possibility for the existence of a liquid-only layer, because the value of $\delta$ is always higher than the value expected for liquid-only particles, $\delta_{\text {liq.only }}$. The existence of solid-only layers is also not likely. The opportunity to have only solid particles appears to be at the altitude of the upper $\delta_{\max }$ layer $(24-25 \mathrm{~km})$, where $\delta$ cannot be clearly distinguished from $\delta_{\text {sol.only }}$ within the limits of the absolute error.

\subsection{Interpretation}

The vertical profiles of $\beta_{l i q}$ and $\beta_{\text {sol }}$ in Fig. 3 (c) reveal that, in general, the backscattering from the liquid particles is larger by one or two orders of magnitude than the backscattering from the solid particles, except for the upper $\delta_{\max }$ layer, where $\beta_{\text {liq }} / \beta_{\text {sol }} \approx 1$. Since the backscattering coefficient of a polydispersion of particles is roughly proportional to the total mass of the particles (Pinnick et al. 1980), it is evident that solid particles should be the nonprevailing species in the altitude range of the cloud, except for the upper $\delta_{\max }$ layer.

The backscattering of the solid particles, $\beta_{\text {sol }}$, takes its maximum value on the order of $10^{-10} \mathrm{~cm}^{-1} \mathrm{sr}^{-1}$ at the altitude of the lower depolarizing layer, around $18 \mathrm{~km}$, while it is on the order of $10^{-11} \mathrm{~cm}^{-1} \mathrm{sr}^{-1}$ for the overall cloud altitude above that layer. However, since $\beta_{\text {liq }}$ is larger at $18 \mathrm{~km}$ than at around $25 \mathrm{~km}$ (the upper depolarizing layer), the observed $\delta$ (Fig. 3 (a)) exhibits higher depolarization at the altitude of the upper depolarizing layer than at the lower one. At the altitude of the $R_{\max }$ layer, the backscattering of solid particles $\left(\beta_{\text {sol }}\right)$ appears to be of the same order as that in the upper depolarizing layer, although this is quite difficult to conclude from Fig. 3 (a). The value of $\alpha$ (Fig. 3 (a)) at the altitude of the upper depolarizing layer is around zero, which indicates the abundance of large particles there. In the lower depolarizing layer, $\alpha$ decreases to around 1 , which also indicates the presence of large particles, although they are masked by the larger abundance of smaller liquid particles.
The value of $\beta_{\text {liq }}$, except for the upper $\delta_{\max }$ layer, is on the order of $10^{-9} \mathrm{~cm}^{-1} \mathrm{sr}^{-1}$, which is considerably higher than expected from the background aerosol layer $\left(\approx 1 \times 10^{-10} \mathrm{~cm}^{-1} \mathrm{sr}^{-1}\right.$ at $\lambda_{1}=0.532 \mu \mathrm{m}$ for particles with a refractive index $n=1.44$ and a lognormal size distribution, from Pinnick et al. (1976)). Hence, if the number concentration of the liquid PSC particles is similar to that of the background aerosol (assumed $10 \mathrm{~cm}^{-3}$ according to Pinnick et al. (1976)), they could be assumed to be larger than the background sulfuric stratospheric aerosol (SSA) particles. Moreover, the observed value of $\alpha$ at the altitude of $R_{\max }$ has a steady value of around 1.2-1.3, which, if compared to the value 1.4 for the background aerosol size distribution cited above, also suggests the existence of slightly larger particles. The presence of solid particles mixed with the liquid ones would not lead to changes in $\alpha$ of more than $10 \%$ because of the small value of the $\beta_{\text {sol }}$ compared to $\beta_{l i q}$.

Figure 3 (e) shows the vertical profile of the temperature measured simultaneously with the OPC, and the profiles of $T_{N A T}, T_{I C E}$ and $T_{S T S}$ calculated for 5 ppmv $\mathrm{H}_{2} \mathrm{O}$ and $15 \mathrm{ppbv}$ $\mathrm{HNO}_{3}$. The existence temperatures of NAT $\left(T_{N A T}\right)$ and ice $\left(T_{I C E}\right)$ are calculated according to Hanson and Mauersberger (1988), and Marti and Mauersberger (1993). For the calculation of the so-called "dew point" of STS, the approximate expression $T_{S T S} \approx T_{N A T}-3.6$ given by Biele et al. (2001) is employed. It can be seen that the largest value of $\beta_{l i q}$ is observed at the altitude where the minimum of the difference $T-T_{I C E}$ is reached. The depolarizing layers are observed at some higher temperature, although still below $T_{N A T}$. The drop in temperature below $T_{S T S}$ indicates activation of the liquid SSA to STS by uptake of $\mathrm{HNO}_{3}$, and $\mathrm{H}_{2} \mathrm{O}$ from the gas phase. As can be seen from the figure, the altitudes for which $T<T_{S T S}$ coincide with those with values of $\beta_{l i q}$ larger than the expected background level.

Figure 3 (d) shows the vertical profiles of the $1-\mathrm{km}$ averaged integrated number concentrations of the aerosol particles in five size categories as observed by OPC simultaneously with the lidar on January $6^{\text {th }}, 1996$. Particle size is discriminated by the OPC for radiuses larger than $0.15,0.25,0.4,0.6$ and $1.8 \mu \mathrm{m}$. 
Comparison between the vertical profiles of the number of particles with $r>1.8 \mu \mathrm{m}\left(N_{r>1.8}\right)$ in Fig. $3(\mathrm{~d})$ and $\beta_{\text {sol }}$ in Fig. 3 (c) reveals rough similarity in the altitude dependence of these two variables. They both reach their largest values at around $18 \mathrm{~km}$ and have a second increase at about $24 \mathrm{~km}$. In the upper depolarizing layer, the increase in $N_{r>1.8}$ is accompanied by an increase in $N_{r>0.6}$. It can be inferred that the radiuses of the solid particles are likely to be larger than $1.8 \mu \mathrm{m}$ (or $>0.6 \mu \mathrm{m}$ in the case of the upper $\delta_{\max }$ layer) and their number concentration is in the range of $10^{-4}-10^{-3} \mathrm{~cm}^{-3}$ for the cloud's altitude range (according to $N_{r>1.8}$, or $N_{r>0.6}$ for the upper $\delta_{\max }$ layer). These number concentrations are consistent with the values derived for the concentrations of the solid particles (assumed NAT) from the numerical simulations in the companion paper (part 2).

Comparison of $\beta_{l i q}$, and the number concentrations of the smaller particles $\left(N_{r>0.15}, N_{r>0.25}\right.$, $N_{r>0.4}$ and $\left.N_{r>0.6}\right)$ also shows similarity in the altitude dependence, but this fact cannot be used as a strong indication of the sizes of the liquid particles. They can, however, be assumed to predominantly have radiuses smaller than $1.8 \mu \mathrm{m}$. At the altitude of $R_{\max }$, the value of $N_{r>0.15}$ is about 6 particles per $\mathrm{cm}^{-3}$ (the largest value for the vertical profile). Hence, taking in to account the probable existence of small $(r<0.15 \mu \mathrm{m})$ liquid particles unaccounted for by the OPC, the total number of the liquid particles at the altitude of $R_{\max }$ layer should be $\geq 6 \mathrm{~cm}^{-3}$.

\section{Summary and conclusions}

A PSC event, detected simultaneously by lidar and OPC at Ny Alesund on January $6^{\text {th }}$, 1996 has been investigated. The PSC exhibits the so-called "sandwich structure" examined earlier in the works of Shibata et al. (1997, 1999). Following the concept of a PSC being an external mixture of solid and liquid particles (e.g., Shibata et al. 1999 and Biele et al. 2001), the backscatter $(R)$ and depolarization $(\delta)$ ratios observed by lidar were employed in equations that allow for the separate calculation of the backscattering coefficients of the liquid $\left(\beta_{l i q}\right)$ and solid $\left(\beta_{\text {sol }}\right)$ particles and for distinction of the mixing state of the cloud. The results from the analysis of the vertical profiles of the lidar data suggest the following.
(1) The entire cloud's altitude can be represented by an external mixture of solid and liquid particles or, the absence of purely liquid or solid layers. For the altitude range of the upper $\delta_{\max }$ layer, however, the results are ambiguous because of the large absolute error there.

(2) The backscattering of the solid particles has similar values, varying by no more than one order of magnitude along the cloud's altitude.

(3) The analysis of the concomitant vertical profile of the temperature reveals that the large values of $\beta_{\text {liq }}^{\text {Lidar }}$ are correlated with the minimum in $T-T_{I C E}$, while the increase in $\beta_{\text {sol }}^{\text {Lidar }}$ can be connected with temperatures that are higher, but still below $T_{N A T}$.

Comparison of the vertical profiles of the lidar data, and the number concentrations of the particles in different size categories observed concomitantly by the OPC implies radiuses $>1.8 \mu \mathrm{m}$ as well as number concentrations of around $10^{-4}-10^{-3} \mathrm{~cm}^{-3}$ for the solid particles.

In the light of these results, the investigated PSC can be considered as composed of a small number of large solid particles coexisting with numerous but smaller liquid particles. The vertical "sandwich structure" of PSCs observed by lidar can be interpreted as a result of the different stages of growth of the liquid particles, which are strongly correlated with the difference $T-T_{S T S}$. In the companion paper (part 2) the different layers of the sandwich structure are simulated numerically via an ensemble of externally mixed STS and NAT particles along the backtrajectory of the PSC.

In conclusion, the developed scheme for the analysis of the lidar data based on the assumption of an external mixture of liquid and solid particles allows for the successful discrimination of the mixing state of the PSC particles. The analysis of the long-term data set from lidar observations above Ny Ålesund, using this method, is a subject for future work.

\section{Acknowledgments}

We thank H. Adachi and M. Watanabe for their help in the lidar and OPC observations. We acknowledge radiosonde data provided by the Alfred Wegner Institute. We also acknowl- 
edge help in conducting our campaigns by the National Institute for Polar Research (NIPR) and Kings Bay Kull Company (KBKC). The Ministry of Education, Arts and Culture, Japan, supported this work as part of the Grantin-Aid for International Scientific Research Program, 07041100 and 09041104.

\section{References}

Adachi, H., 1996: The external mixing state of polar stratospheric clouds observed by lidar: Methodology for analysis (in Japanese). Master thesis, Nagoya Univ., Nagoya, Japan.

, T. Shibata, Y. Iwasaka, and M. Fujiwara, 2001: Calibration method for the lidar-observed stratospheric depolarization ratio in the presence of liquid aerosol particles. Appl. Opt., 40, 6587-6595.

Biele, J., A. Tsias, B.P. Luo, K.S. Carslaw, R. Neuber, G. Beyerle, T. Peter, 2001: Nonequilibrium coexistence of solid and liquid particles in Arctic stratospheric clouds. J. Geophys. Res., 106, 22991-23007.

Browell, E.V., C.F. Butler, S. Ismail, P.A. Robinette, A.F. Carter, N.S. Higdon, O.B. Toon, M.R. Schoeberl, and A.F. Tuck, 1990: Air-borne lidar observations in the wintertime arctic stratosphere: Polar stratospheric clouds. Geophys. Res. Lett., 17, 385-388.

Carslaw, K.S., B.P. Luo, S.L. Clegg, T. Peter, P. Brimblecombe, and P.J. Crutzen, 1994: Stratospheric aerosol growth and $\mathrm{HNO}_{3}$ gas phase depletion from coupled $\mathrm{HNO}_{3}$ and water uptake by liquid particles. Geophys. Res. Lett., 21, 2479-2482.

Crutzen, P.J. and F. Arnold, 1986: Nitric acid cloud formation in the cold Antarctic stratosphere: A major cause for the springtime ozone hole. Nature, 324, 651-654.

Drdla, K., A. Tabazadeh, R.P. Turco, M.Z. Jacobson, J.E. Dye, C. Twohy, and D. Baumgardner, 1994: Analysis of the physical state of one Arctic polar stratospheric cloud based on observations. Geophys. Res. Lett., 21, 2475-2478.

Gobbi, G.P., G. Di Donfrancesco, and A. Adriani, 1998: Physical properties of stratospheric clouds during the Antarctic winter of 1995. J. Geophys. Res., 103, 10859-10873.

Hanson, D.R. and K. Mauersberger, 1988: Laboratory studies of the nitric acid trihydrate: Implications for the south polar stratosphere. $G e$ ophys. Res. Lett., 15, 855-858.

Hayashi, M., Y. Iwasaka, M. Watanabe, T. Shibata, M. Fujiwara, H. Adachi, T. Sakai, M. Nagatani, and M. Tsuchiya, 1998: Size and number concentration of liquid PSCs: Balloon-borne meas- urements at Ny-Ålesund, Norway in winter of 1994/1995. J. Meteor. Soc. Japan, 76, 549-560.

Iraci, L.T., T.J. Fortin, and M.A. Tolbert, 1998: Dissolution of sulfuric acid tetrahydrate at low temperatures and subsequent growth of nitric acid trihydrate. J. Geophys. Res., 103, 84918498.

Kent, G.S., L.R. Poole, M.P. McCormick, S.K. Schaffner, W.H. Hunt, and M.T. Osborn, 1990: Optical backscattering characteristics of Arctic polar stratospheric clouds. Geophys. Res. Lett., 17, 377-380.

Marti, J. and K. Mauersberger, 1993: A survey and new measurements of ice vapor pressure at temperatures between 170 and $250 \mathrm{~K}$. Geophys. Res. Lett., 20, 363-366.

Poole, L.R. and M.P. McCormick, 1988: Polar stratospheric clouds and the ozone hole. J. Geophys. Res., 93, 8423-8430.

Pinnick, R.G., J.M. Rosen, and D.J. Hofmann, 1976: Stratospheric aerosol measurements III: Optical model calculations. J. Atmos. Sci., 33, 304314.

, S.G. Jennings, and P. Chýlek, 1980: Relationships between extinction, absorption, backscattering, and mass content of sulfuric acid aerosol. J. Geophys. Res., 85, 4059-4066.

Rosen, J.M., N.T. Kjome, N. Larsen, B.M. Knudsen, E. Kyrö, R. Kivi, J. Karhu, R. Neuber, and I. Beninga, 1997: Polar stratospheric clouds threshold temperatures in the 1995-1996 Arctic vortex. J. Geophys. Res., 102, 28195-28202.

Russell, P.B., T. Swissler, and M.P. McCormick, 1979: Methodology for error analysis and simulation of lidar aerosol measurements. Appl. Opt., 18, 3783-3797.

Shibata, T., T. Sakai, M. Hayashi, T. Ojio, S. Kwon, Y. Iwasaka, 1996: Raman Lidar Observations: Simultaneous Measurements of Water Vapor, Temperature and Aerosol Vertical Profiles, Part II. J. Geomagn. Geoelectr., 48, 1137-1144.

Shibata, T., Y. Iwasaka, M. Fujiwara, M. Hayashi, M. Nagatani, K. Shiraishi, H. Adachi, T. Sakai, K. Susumu, and Y. Nakura, 1997: Polar stratospheric clouds observed by lidar over Spitsbergen in the winter of 1994/1995: Liquid particles and vertical "sandwich" structure. J. Geophys. Res., 102, 10829-10840.

, K. Shiraishi, H. Adachi, Y. Iwasaka, and M. Fujiwara, 1999: On the lidar-observed sandwich structure of polar stratospheric clouds (PSCs) 1. Implications for the mixing state of the PSC particles. J. Geophys. Res., 104, 21603-21611.

, 1999: On the lidar-observed sandwich structure of polar stratospheric clouds (PSCs) 2. Numerical simulations of externally mixed 
PSC particles. J. Geophys. Res., 104, 2161321619.

Solomon, S., R.R. Garcia, F.S. Rowland, and D.J. Wuebbles, 1986: On the depletion of Antarctic ozone. Nature, 321, 755-758.

Stanford, J.L. and J.S. Davis, 1974: A century of stratospheric cloud reports: 1870-1972. Bull. Amer. Meteor. Soc., 55, 213-219.

Steel, H.M., P. Hamill, M.P. McCormick, and T.J. Swissler, 1983: The formation of polar stratospheric clouds. J. Atmos. Sci., 12, 517-528.
Tabazadeh, A., R.P. Turco, K. Drdla, M.Z. Jacobson, and O.B. Toon, 1994: A study of type I polar stratospheric cloud formation. Geophys. Res. Lett., 21, 1619-1622.

Tolbert, M.A., 1994: Sulfate aerosols and polar stratospheric cloud formation. Science, 264, 527528.

Worsnop, D.R., L.E. Fox, M.S. Zahniser, and S.C. Wofsy, 1993: Vapor pressure of solid hydrates of nitric acid: Implications for polar stratospheric clouds. Science, 259, 71-74. 